Supporting Information

\title{
A Switchable Self-doped Polyaniline: Interconversion Between Self-doped and Non-self-doped Forms
}

Bhavana A. Deore, Insun Yu and Michael S. Freund ${ }^{*}$

Department of Chemistry, University of Manitoba, Winnipeg, Manitoba, R3T 2N2

\section{Experimental Section}

General information. 3-Aminophenylboronic acid hydrochloride salt, Dfructose and ammonium persulfate were purchased from Aldrich Chemical Inc. Sodium fluoride and $\mathrm{pH} 7.4$ phosphate buffer saline stock solution (10X), were purchased from Fisher Scientific. Bulk distilled water was first filtered and ion exchanged to yield 18.3 M $\Omega$ quality water using an EasyPure RF, Barnstead Thermolyne Model 7031.

Preparation of Poly(2). Water soluble poly(2) in the presence of D-fructose and fluoride was synthesized as follows: Aqueous $40 \mathrm{mM}$ ammonium persulfate $(0.5 \mathrm{ml}$, oxidizing agent) was slowly added over a period of $10 \mathrm{~min}$ to an aqueous mixture (19.5 $\mathrm{ml}$ ) of $40 \mathrm{mM} 3$-aminophenylboronic acid, $40 \mathrm{mM}$ sodium fluoride and $10 \mathrm{M} \mathrm{D}$-fructose. The $\mathrm{pH}$ of the reaction mixture was 7 before adding oxidizing agent. The mixture was stirred overnight at room temperature. In a similar manner poly(2) could also be prepared in phosphate buffer saline solution ( $\mathrm{pH}$ 7.4). The water soluble poly(2) formed using both methods was easily passed through a $0.02 \mu \mathrm{m}$ Anotop filter (Whatman). The polymer produced under these conditions was readily precipitated by diluting the solution $(\sim 3 \mathrm{X}$ volume with pure water) and in turn reducing the fluoride concentration. The resulting precipitate was redispersed in water and centrifuged more than 20 times to remove the excess D-fructose and reactants.

Characterization. UV-vis spectra were obtained using an Agilent 8453 spectrophotometer. Cyclic voltammetric measurements were performed using a $\mathrm{CH}$ Instrument CHI-660 workstation controlled by a PC. A three electrode cell was used, which consisted of a glassy carbon disk working electrode (Bioanalytical Systems, 3.0$\mathrm{mm}$ diameter), a platinum coil auxiliary electrode, and a $\mathrm{Ag} / \mathrm{AgCl}$ reference electrode. Cyclic voltammograms were conducted in a $0.5 \mathrm{M} \mathrm{HCl}$ aqueous solution with a scan rate of $100 \mathrm{mV}_{-} \mathrm{s}^{-1}$. Infrared spectra were obtained using a Bomem FT-IR spectrometer (Hartmann and Braun). Polymer samples were mixed with $\mathrm{KBr}$ powder to prepare pellets 
for IR measurements. ${ }^{11}$ B NMR studies were carried out using a Bruker AMX 500 NMR spectrophotometer. The monomer samples used for NMR measurements were prepared using $10 \% \mathrm{D}_{2} \mathrm{O}$ in phosphate buffer saline solution ( $\mathrm{pH}$ 7.4). Monomer sample preparation details are given in Table 1. Elemental analyses were carried out by Chemisar Laboratories Inc.

Molecular weight was determined with gel permeation chromatography (GPC) using polystyrene standards to calibrate the column in NMP. A Polymer Laboratories Inc. PLgel $5 \mu \mathrm{m}$ MIXED-C column was used, operating at $70{ }^{\circ} \mathrm{C}$. The concentration of the polymer samples were $0.033 \mathrm{mg} / \mathrm{ml}$. A MiniDAWN Tristar detector (Wyatt Technology), operating at $690 \mathrm{~nm}$, was used as the absorbance detector. Prior to GPC experiments the polymers were dissolved in NMP with constant stirring for $48 \mathrm{~h}$ and filtered through a $0.02 \mu \mathrm{m}$ Anotop filter. 


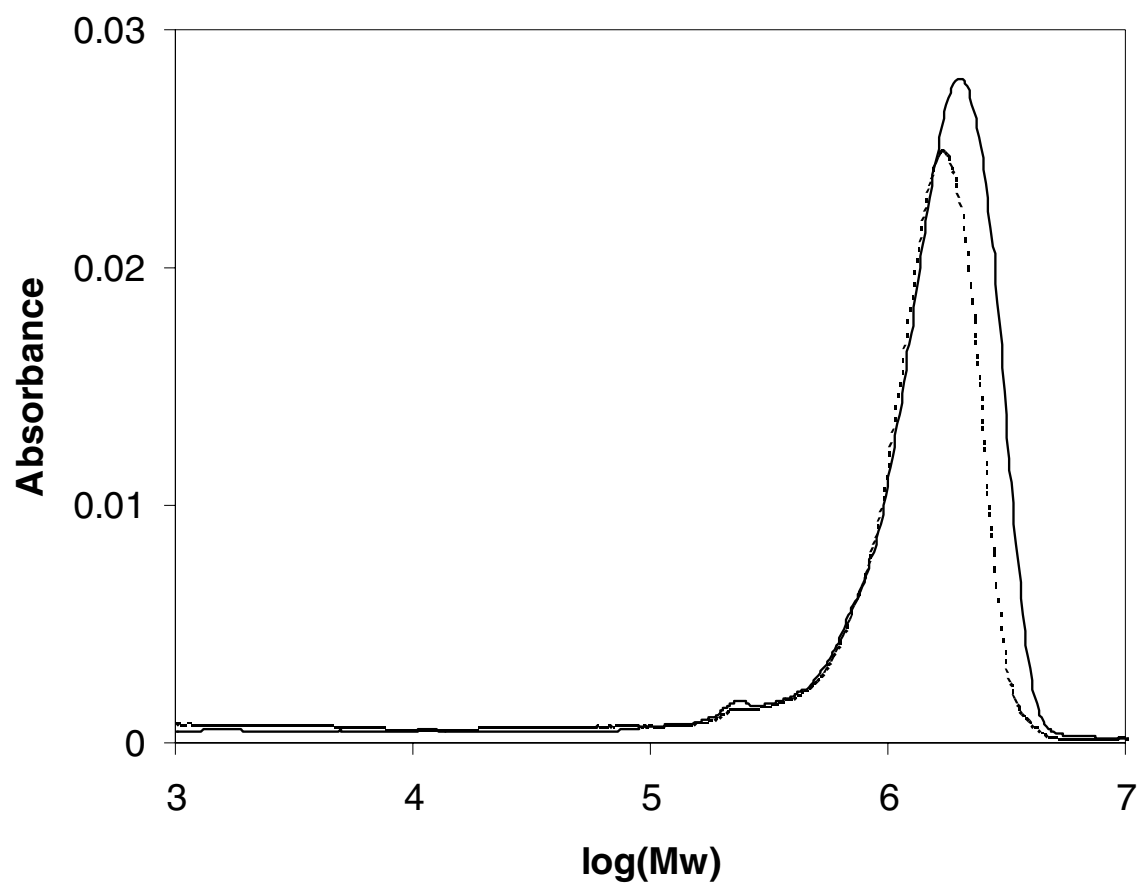

Figure. GPC chromatograms for $0.033 \mathrm{mg} / \mathrm{ml}$ of Poly(1) (solid line) and $\operatorname{poly}(\mathbf{2})$ (dashed line) dissolved in NMP.

Table. 1. ${ }^{11}$ B NMR chemical shifts of 3-aminophenylboronicacid (3-APBA) adducts

Solution conditions

${ }^{11} \mathrm{~B}$ chemical shift (ppm)

$40 \mathrm{mM} 3-\mathrm{APBA}(\mathrm{pH}=7.4)$

29.2

$40 \mathrm{mM}$ 3-APBA $+40 \mathrm{mM} \mathrm{NaF}+10 \mathrm{M}$ Fructose $(\mathrm{pH}=7.4)$

6.4

Shifts measured relative to reference borontrifluoride etherate 